\title{
Spatial distribution of polychlorinated dibenzo- $p$-dioxins and polychlorinated dibenzofurans in soil around a municipal solid waste incinerator
}

\author{
Wenbin Liu • Haifeng Li $\cdot$ Zhenyu Tian • \\ Huiting Xie $\cdot$ Changliang Li
}

Received: 26 October 2012/Accepted: 2 April 2013/Published online: 26 June 2013

(C) Springer Science+Business Media Dordrecht 2013

\begin{abstract}
Municipal solid waste incinerators (MSWIs) are usually considered to be important sources of polychlorinated dibenzo- $p$-dioxins and polychlorinated dibenzofurans (PCDD/Fs). To examine the influence of PCDD/Fs emissions from a MSWI on the surrounding environment, 21 soil samples were collected from various sampling sites distributed at distances of 300-1,700 $\mathrm{m}$ away from the stack of a MSWI. International Toxic Equivalent (I-TEQ) concentrations ranged from 0.47 to $2.07 \mathrm{pg}$ I-TEQ $\mathrm{g}^{-1}$, with average and median concentrations of 1.08 and 1.05 pg I-TEQ $\mathrm{g}^{-1}$, respectively. Comparison of the results presented herein with other worldwide studies suggested that the concentrations of PCDD/Fs in the ambient soil were relatively low, indicating a limited impact on the surrounding environment. The emission concentrations from the incinerator were the critical factor in generating an environmental impact on the surrounding environment. An exponential function was developed, indicating a slight decline in TEQs of PCDD/Fs with increasing distance from the MSWI stack. The ordinary kriging interpolation technique was selected to create a contour
\end{abstract}

Electronic supplementary material The online version of this article (doi:10.1007/s10653-013-9543-x) contains supplementary material, which is available to authorized users.

W. Liu $(\bowtie) \cdot$ H. Li $\cdot$ Z. Tian $\cdot$ H. Xie $\cdot$ C. Li

State Key Laboratory of Environmental Chemistry and Ecotoxicology, Research Center for Eco-Environmental Sciences, P.O. Box 2871, Beijing 100085, China

e-mail: liuwb@rcees.ac.cn map, which intuitively showed that a limited surrounding area $(\leq 1,000 \mathrm{~m}$ from the stack) was obviously influenced by the MSWI.

Keywords Exponential function - Contour map · Ordinary kriging $\cdot$ Surrounding soil

\section{Introduction}

Polychlorinated dibenzo-p-dioxins and dibenzofurans (PCDD/Fs) are among the persistent organic pollutants targeted for international source reduction by the Stockholm Convention. PCDD/Fs are stable in the environment, undergo long-range transport in the atmosphere and can bioaccumulate in the ecosystem via the food chain ( $\mathrm{Li}$ et al. 2008). Unintentionally produced $\mathrm{PCDD} / \mathrm{Fs}$ can be released into the environment from various thermal processes (Fiedler 1996; Kulkarni et al. 2008; Schuhmacher et al. 1997). Among these processes, municipal solid waste incineration, as an important $\mathrm{PCDD} / \mathrm{Fs}$ emission source, is closely linked with people's lives and therefore causes widespread public concern (Lu et al. 2012; Lee et al. 2007).

PCDD/Fs have high octanol/water partition coefficient values (Log Kow $>5.0)$ and low vapor pressures $\left(P<10^{-8} \mathrm{~atm}\right)$ (Fries 1995). Therefore, they readily accumulate in the environment, especially in organic carbon-rich media such as soil, sediment and biota (Meneses et al. 2002; Polder et al. 2008). Among these 
media, soil has been demonstrated to act as a conservative matrix for the atmospheric deposition of PCDD/Fs and to reflect long-term exposure (Brzuzy and Hites 1995). To date, many researchers have focused on the concentrations of PCDD/Fs in ambient soil around municipal solid waste incinerators (MSWIs) and their impact on the environment (Caserini et al. 2004; Rovira et al. 2010; Lorber et al. 1998). The concentrations of PCDD/Fs have shown wide variation in soils. High concentrations of $\mathrm{PCDD} / \mathrm{Fs}$ were detected in the soils around MSWIs in Korea (Oh et al. 2006), France (Pirard et al. 2004) and Spain (Domingo et al. 2000), indicating a significant influence on the ambient soil. However, some researchers have suggested that there were no obvious effects on the surrounding environment based on relatively low concentrations of PCDD/Fs in the soil (Cheng et al. 2003; Liu et al. 2012). Therefore, further analysis and monitoring of concentrations of $\mathrm{PCDD} / \mathrm{Fs}$ in soil are warranted to investigate the influence of emission sources of PCDD/Fs on the surrounding environment.

As the largest developing country in the world, China generated 221 million tons of municipal solid waste (MSW) in 2010. About 21.2 million metric tons of MSW were treated by incineration with a daily treatment capacity of 58,100 tons. A lack of landfill sites has led to incineration becoming an alternative effective and efficient means of treating waste, which has led to increasing public concern over potential adverse environmental and health effects of PCDD/Fs emitted from MSWIs.

In this study, a series of soil samples were collected in the vicinity of a MSWI to investigate the influence of the MSWI on the surrounding environment. A continuous map of PCDD/Fs concentrations in the soil samples was then created using ordinary kriging interpolation analysis, and the relationship between the distance from the stack of the MSWI and PCDD/Fs concentrations in soil was evaluated. This study is expected to be helpful for estimating PCDD/Fs released into the ambient environment and answering public concerns pertaining to MSWIs.

\section{Materials and methods}

Stack gas sampling

The Sunrise Municipal Solid Waste Incineration Plant, located in Tianjin municipality, China, was investigated in this study. This MSWI is located in a complex zone that includes residential areas, schools and shopping malls, but no heavy industry. The MSWI was put into service in October 2003 and has a treatment capacity of 1,600 tons per day. The combustion system consists of two grate furnaces with a stack of $80 \mathrm{~m}$, and the stack gas cleaning system contains a semi-dry scrubber, an active carbon injector and a bag filter.

Stack gas samples were isokinetically collected from the stack of the MSWI according to the Chinese national guidelines (HJ77.2) using the ISO BASIC System (Tecora Corp., Milan, Italy). During sampling, gaseous phase samples were collected by the XAD-2 resin and condensed water, while the particulate phases were trapped by the quartz-fiber unit. Additionally, a sampling standard (Wellington Laboratories, Guelph, Canada) was spiked into the XAD2 resin before sampling of the stack gas. After sampling, the probe liners were washed with acetone and the washing solutions were retained for analysis. All analytical samples (the filter, XAD-2 resin, concentrated water and washing solution) were stored in darkness and analyzed as soon as possible after sampling.

\section{Soil sampling}

A total of 21 soil samples were collected at distances of $300-1,700 \mathrm{~m}$ from the stack of the MSWI in February 2012 from various sampling sites distributed around the MSWI (Fig. S1). The sampling sites were selected according to the Atmospheric Dispersion Modeling System (ADMS) and the wind rose diagram and were influenced by some specific local conditions. Meteorological data were obtained from the local meteorological administration. The exact positions of the sampling sites were recorded by a portable GPS device (Magellan GPS, San Dimas, CA, USA). Three concentric circles around the location of the stack of the MSWI represented radii of $500,1,000$ and $1,500 \mathrm{~m}$ from the incinerator.

Each soil sample was collected by mixing five different aliquots based on the five plum distribution method within a $25 \mathrm{~m}^{2}$ area. About $2 \mathrm{~kg}$ of soil was collected with a metal hand-operated sampler to a depth of about $10 \mathrm{~cm}$ from the soil surface. Plant materials such as roots and leaves were manually removed, after which the samples were dried to a 
constant weight, ground and homogenized through a 60-mesh sieve, and then refrigerated prior to analysis.

Of the 21 soil samples, 18 were collected within $1,500 \mathrm{~m}$ of the stack and a further three samples were collected between 1,500 and $1,700 \mathrm{~m}$. An additional background soil sample was collected near a rural reservoir located $50 \mathrm{~km}$ away from the MSWI, which can be considered to be not influenced by the incinerator and any other industrial sources.

\section{PCDD/Fs analysis}

PCDD/Fs analysis was performed according to the US Environmental Protection Agency (EPA) Method 1613. Briefly, the samples were spiked with $1 \mathrm{ng}$ of a ${ }^{13} \mathrm{C}_{12}$-labeled PCDD/Fs internal standard (Wellington Laboratories) (Wu et al. 2011) before accelerated solvent extraction (hexane/dichloromethane $=1: 1$ ). The extract was then sequentially cleaned using a multilayer silica gel and basic alumina columns. The final extract was concentrated to $20 \mu \mathrm{l}$ and spiked with $1 \mathrm{ng}$ of ${ }^{13} \mathrm{C}_{12}$-labeled injection standard for recovery quantification before analysis using an Agilent 6890 high resolution gas chromatograph/Waters Autospec Ultima high resolution mass spectrometer (HRGC/ HRMS) with a DB-5 MS column. The HRMS was operated in SIM mode at $\mathrm{R} \geq 10,000$. Field and laboratory blanks were incorporated into the analytical procedure for quality control. The recovery range of 17 congeners of 2,3,7,8-PCDD/Fs was between 42.6 and $117.6 \%$, which satisfied the requirements of US EPA method 1613.

\section{Statistical analysis}

The geostatistical interpolation technique was used to create a continuous map of PCDD/Fs concentrations in the soil samples with the widely used ordinary kriging algorithm. The map was produced using Golden Software Surfer 8.0 with cross-validations. In addition, the relationship between the distance from the stack of the MSWI and the toxic equivalents (TEQs) of $\mathrm{PCDD} / \mathrm{Fs}$ in soil samples was evaluated through an exponential function equation on the basis of the Gaussian plume diffusion model. When fitting the regression model, it was assumed that the relationships being modeled were the same everywhere within the study area from which the data were drawn.

\section{Results and discussion}

PCDD/Fs concentrations in the samples

The concentrations of PCDD/Fs in three stack gas samples of the MSWI were analyzed to investigate the MSWI emissions. The total concentrations of 2,3,7,8PCDD/Fs in the three stack gas samples were 521.19, 518.09 and $932.94 \mathrm{pg} \mathrm{m}^{-3}$, and the corresponding TEQs were 44.83, 42.32 and 67.38 pg I-TEQ $\mathrm{m}^{-3}$, respectively, based on the International Toxic Equivalent Factors (Kutz et al. 1990). 2,3,4,7,8-PeCDF was the most important congener contributing to I-TEQs, regardless of the PCDD/F concentrations, accounting for $45.22 \%$ of the toxic equivalents. In addition, 12 stack gas samples in four batches were measured regularly for their PCDD/Fs emissions in 2011 by our group. The concentrations of $\mathrm{PCDD} / \mathrm{Fs}$ in these samples ranged from 0.003 to $0.098 \mathrm{ng}$ I-TEQ $\mathrm{m}^{-3}$, which was below the legal limit of $0.1 \mathrm{ng}^{\mathrm{I}-T E Q ~ \mathrm{~m}^{-3}}$.

The concentrations of $2,3,7,8-\mathrm{PCDD} / \mathrm{Fs}$ in the ambient soil samples were presented in Table S1. The total concentrations of $2,3,7,8-\mathrm{PCDD} / \mathrm{Fs}$ in the ambient soil samples ranged from 14.68 to $63.02 \mathrm{pg} \mathrm{g}^{-1}$, with average and median concentrations of 33.46 and $33.84 \mathrm{pg} \mathrm{g}^{-1}$, respectively, while

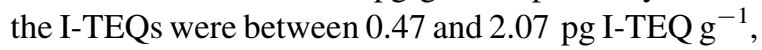
with average and median concentrations of 1.08 and $1.05 \mathrm{pg} \mathrm{I-TEQ} \mathrm{g}^{-1}$, respectively. As a comparison, the concentrations of total 2,3,7,8-PCDD/Fs and I-TEQ in the background soil sample collected about $50 \mathrm{~km}$ away from the MSWI were only $16.30 \mathrm{pg} \mathrm{g}^{-1}$ and $0.46 \mathrm{pg}$ I-TEQ $\mathrm{g}^{-1}$, respectively. The PCDD/Fs concentrations in the ambient soils of the MSWI were one to four times higher than the background sample. OCDD was generally the highest congener in concentrations among all ambient soil samples of the MSWI, ranging from 5.82 to $44.40 \mathrm{pg} \mathrm{g}^{-1}$. In addition, the percentages of OCDD in the total $2,3,7,8-\mathrm{PCDD} / \mathrm{Fs}$ ranged from 35.74 to $84.11 \%$, with an average of $50.98 \%$. PCDFs were the primary contributors to the total TEQs, and the corresponding contribution rates ranged from 32.46 to $86.52 \%$, with an average of $65.30 \%$. 2,3,4,7,8-PeCDF and 2,3,7,8-TCDD were dominant among the 17 measured toxic congeners, accounting for 28.48 and $14.62 \%$ of the total TEQ, respectively. Principal component analysis (PCA) was used to provide relationships between the concentrations of PCDD/Fs in the soil and stack gas samples. 
A congener-specific factor analysis with 17 congeners of PCDD/Fs was performed using SPSS software, with three stack gas samples and 21 soil samples selected as the variables. In the component plot (Fig. S2), all ambient soil samples were clustered into a group, showing similar PCDD/Fs sources. The stack gas samples constituted another cluster. The difference in the patterns between the soil and stack gas samples may be explained by different efficiencies of deposition and degradation of different PCDD/Fs congeners in the soil.

To gain perspective on the relative concentrations of PCDD/Fs in soils in the vicinity of MSWIs, the I-TEQs were compared with those observed in a number of investigations worldwide. The wide variation of the PCDD/Fs concentrations in the soil indicated that the PCDD/Fs concentration of the stack gas was the critical factor in generating an environmental impact on the surrounding environment. Also, high concentrations of $\mathrm{PCDD} / \mathrm{Fs}$ are usually associated with MSWIs equipped with poor facilities that have been found to have significant impacts on the ambient soil, while MSWIs with good pollution control facilities have little impact on the surrounding environment owing to their relatively low PCDD/Fs emission.

Incinerators equipped with poor facilities have been found to be associated with significant impacts on the ambient soil surrounding facilities in several studies. For example, high concentrations of $\mathrm{PCDD} / \mathrm{Fs}$ were detected in the ambient soil in Korea (Oh et al. 2006), with concentrations of $\mathrm{PCDD} / \mathrm{Fs}$ ranging from 1.25 to $74.98 \mathrm{pg}$ I-TEQ $\mathrm{g}^{-1}$ and an average of $19.06 \mathrm{pg}$ I-TEQ $\mathrm{g}^{-1}$ within $1 \mathrm{~km}$ of the MSWI. The MSWI investigated in that study was put into service in 1995 and had a treatment capacity of 200 tons day ${ }^{-1}$. In 1997, the PCDD/Fs emissions from this incinerator were recorded as being the highest in Korea. A study conducted in France (Pirard et al. 2004) revealed quite high concentrations in the soil surrounding a MSWI, with values ranging from 3.26 to 59.04 pg WHOTEQ $\mathrm{g}^{-1}$. The incinerator investigated in that study began to operate in 1974 with a capacity of 96 tons day $^{-1}$, and the measured dioxin concentration in the stack gas was $226 \mathrm{ng}$ WHO-TEQ $\mathrm{m}^{-3}$, which was more than 2000-fold higher than the actual European norm of $0.1 \mathrm{ng}$ TEQ $\mathrm{m}^{-3}$. Domingo et al. (2000) investigated the soil contamination around an old incinerator plant in Spain and found that the PCDD/Fs concentrations ranged from 1.33 to $54.23 \mathrm{pg}$
I-TEQ $\mathrm{g}^{-1}$. The facility began operations in 1975 and handled about 300,000 tons of MSW per year without emission control devices.

In contrast, incinerators with good pollution control facilities have little impact on the surrounding environment. Low concentrations of $\mathrm{PCDD} / \mathrm{Fs}$ in soil

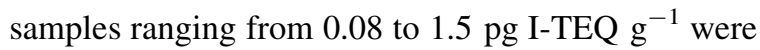
found in the vicinity of a facility in Italy (Caserini et al. 2004). The three incinerators were equipped with activated carbon, a fabric filter and a wet scrubber. Rovira et al. (2010) conducted a systematic study of soils near a MSWI with modern facilities in Spain and found similarly low PCDD/Fs concentrations (0.14-0.46 pg WHO-TEQ $\mathrm{g}^{-1}$ ). Cheng et al. (2003) measured the PCDD/Fs concentrations in ambient soil within $8 \mathrm{~km}$ of the Hsinchu MWSI in Taiwan and found that the concentrations of $\mathrm{PCDD} / \mathrm{Fs}$ ranged from

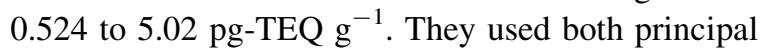
component analysis and hierarchical cluster analysis to suggest that the MSWI was not the primary source of the PCDD/Fs contamination of the environment they studied. Relatively low concentrations of PCDD/Fs were detected in the ambient soil samples of an incineration plant with a capacity of about 300,000 tons in China. The concentrations in the soil samples ranged

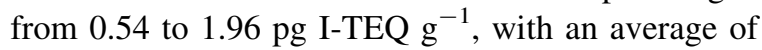
$1.33 \mathrm{pg}$ I-TEQ $\mathrm{g}^{-1}$, while the concentrations of $\mathrm{PCDD} / \mathrm{Fs}$ in the stack gas samples were below $0.1 \mathrm{ng}$ I-TEQ $\mathrm{m}^{-3}$. PCA and HCA showed that the MSWI investigated in that study only had the potential to influence the environment and that emissions from traffic also played an important role (Lu et al. 2012). Also, the PCDD/Fs emission of the MSWI investigated in this study was lower than the legal limit of $0.1 \mathrm{ng}$ I-TEQ $\mathrm{Nm}^{-3}$, and the concentrations of PCDD/Fs in the ambient soil were relatively low, indicating a limited impact on the surrounding environment.

\section{Relationship between distance and PCDD/Fs concentrations}

Figure 1 showed the variation in PCDD/Fs concentrations in soil samples collected at different distances from the stack of the MSWI. To conduct a preliminary analysis of the relationship between distance and the PCDD/Fs concentrations in soils, 21 soil samples were roughly divided into six groups with increasing distances (250-500, 500-750, 750-1,000, 1,000-1,250, $1,250-1,500$ and $1,500-1,750 \mathrm{~m}$ ) from the stack. Every 
$250 \mathrm{~m}$, the data were summarized into one group and the average of the TEQs was calculated.

An exponential function equation [Eq. (1)] was proposed to simulate the Gaussian plume diffusion model within the limited range investigated in this study (Fig. 1). In the equation, " $y$ " represented the TEQs of PCDD/Fs in the soil, while " $x$ " represented the distance from the stack of the MSWI. The $R^{2}$ of the equation was 0.51 .

$y=1.51 \times \exp (-0.0003 x)$

When PCDD/Fs concentrations tend to decrease as the distance from a certain site increases, the site can be considered a source of PCDD/Fs (Oh et al. 2006). From Eq. (1), it can be seen that PCDD/Fs concentrations declined slightly with increasing distance from the stack, which supported the conclusion that the MSWI was a source of the PCDD/Fs in the surrounding soil. High PCDD/Fs concentrations were detected in most soil samples collected from sites near the stack, and the maximum PCDD/Fs concentration was observed at 500-750 $\mathrm{m}$ from the MSW incineration plant. These findings were in accordance with a previous study (Yan et al. 2008), in which the maximum PCDD/Fs concentration around a MSWI was also observed at 500-750 $\mathrm{m}$ from the stack, and a decline with increasing distance was seen in 33 soil samples.

\section{Comparison of homologue patterns}

Comparison of homologue patterns was commonly used to investigate the relationship between stack gas and soil samples (You et al. 2011; Lu et al. 2012).

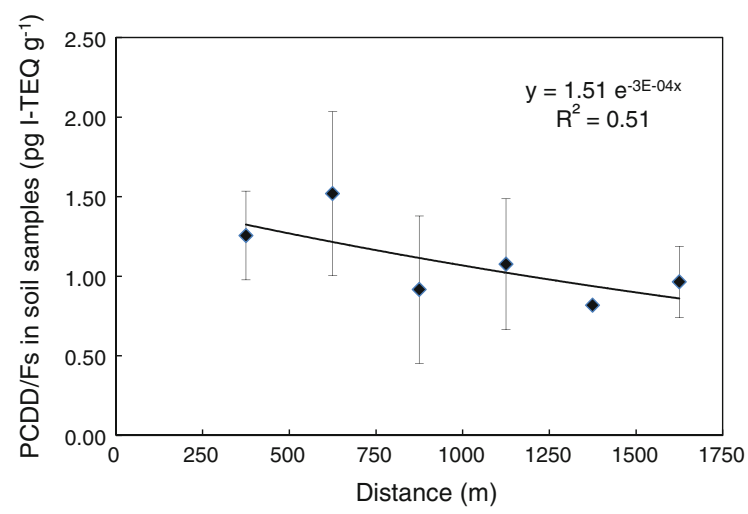

Fig. 1 Relationship between distances from the MSWI and PCDD/Fs concentrations, with error bars indicating the standard deviation
Figure S3 showed the homologue patterns of PCDD/ Fs in the stack gas and soil samples. As mentioned above, all soil samples were divided into six groups according to their distance from the stack. The samples in each 250-meter increment were grouped, and the PCDD/Fs concentrations in each group were averaged. The homologue profiles in the soil samples were similar, showing differences from the stack gas. PCDFs were the primary contributors to the total concentration of PCDD/Fs in the stack gas samples, while PCDDs were dominant among the soil samples.

Many studies have reported that the fraction of PCDFs in stack gases is higher than that of PCDDs, which differs from the results observed for soil samples (Ogura et al. 2001; Lu et al. 2012). The ratios of the total concentrations of PCDDs and PCDFs (D/F ratios) are commonly used as indicators of homologue patterns (Xu et al. 2009; Gaus et al. 2001). In this study, the average $\mathrm{D} / \mathrm{F}$ ratios in the six groups of soil samples were 1.31, 1.88, 1.39, 1.60, 2.22 and 2.06, respectively, which were all higher than that of the stack gas (0.35). These findings may be explained by the fact that the PCDDs are more stable than PCDFs and that $\mathrm{D} / \mathrm{F}$ ratios gradually increase in the soil after the deposition and degradation of PCDD/Fs from the stack gas.

\section{Contour maps of PCDD/Fs}

The geostatistical interpolation technique has been widely applied to create continuous contour maps, which is a general designation of a series of equivalent lines distributed on a map (Si et al. 2010). To analyze the spatial characteristics of PCDD/Fs in ambient soil samples around the MSWI, the widely used ordinary kriging interpolation technique was selected to create a contour map of PCDD/Fs concentrations in the soil samples (Fig. 2) (Dao et al. 2012; Carr et al. 2008).

Four regions with relatively high concentrations were regularly distributed around the stack, and the highest PCDD/Fs concentration was observed northeast of the stack of the MSWI. When the abscissa or ordinate were about $\pm 500 \mathrm{~m}$, corresponding to about 500-1,000 $\mathrm{m}$ from the stack, the concentrations of $\mathrm{PCDD} / \mathrm{Fs}$ were higher than in other regions. These findings indicated that these locations were near the deposition points of PCDD/Fs during the deposition process. Also, the simulated results obtained from the ADMS model also indicated that the deposition points 
Fig. 2 Contour map of PCDD/Fs concentrations (pg I-TEQ $\mathrm{g}^{-1}$ ) in the soil samples. The coordinate $(0,0)$ represented the position of the stack of the MSWI

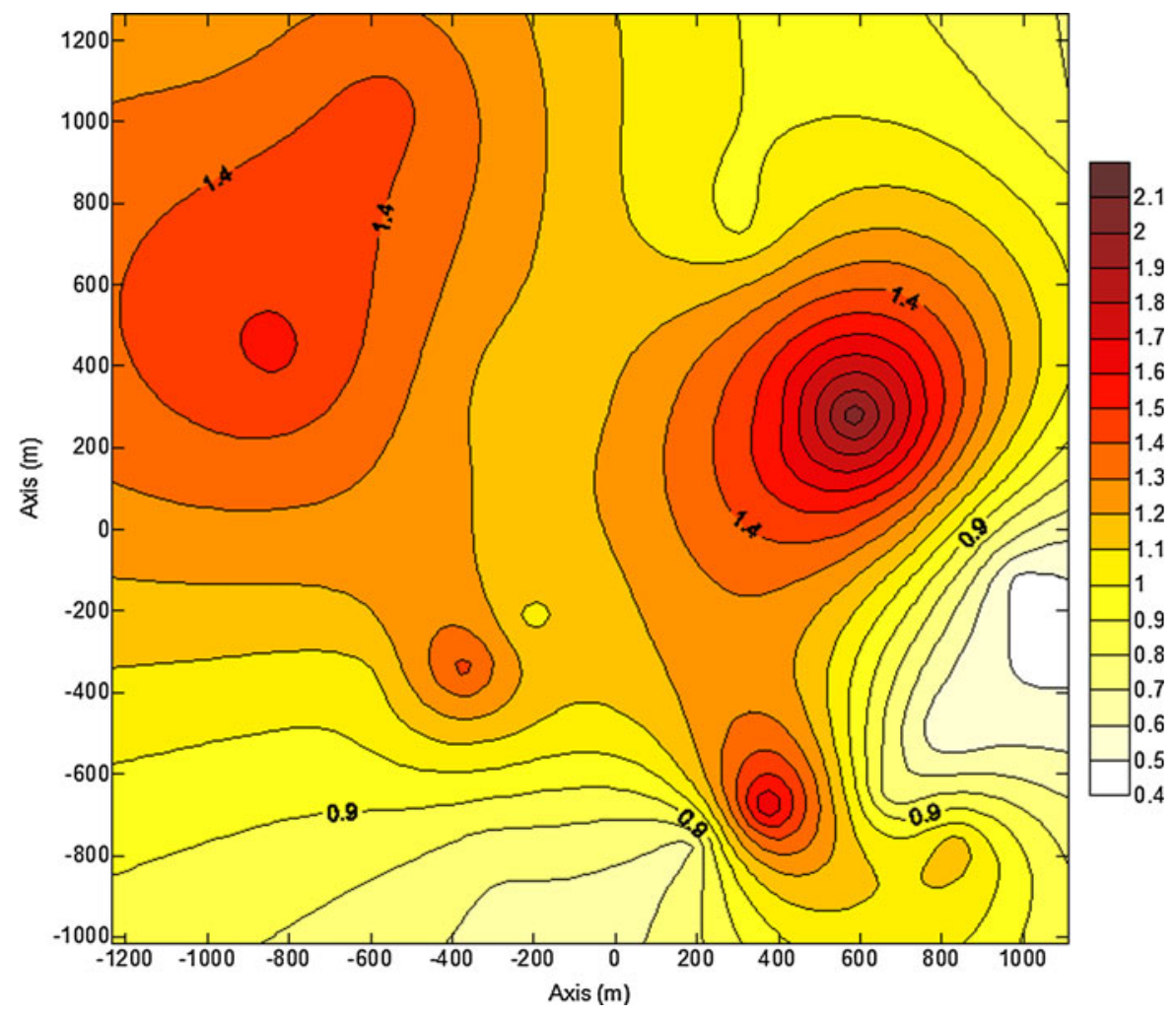

of PCDD/Fs were about $500 \mathrm{~m}$ away from the stack, which confirmed the analysis results. Therefore, the distance from the stack of the MSWI was a major factor influencing the impact of the MSWI on the surrounding environment. Notable variations and high concentrations of PCDD/Fs appeared in the samples at $\leq 1,000 \mathrm{~m}$ from the stack, suggesting that a limited surrounding area was obviously influenced by the MSWI. In contrast, there was no significant variation in regions $>1,000 \mathrm{~m}$ from the stack, indicating the absence of a marked effect on areas farther away. These findings coincided with the long-term monitoring of $\mathrm{PCDD} / \mathrm{Fs}$ around an incinerator in China (Li et al. 2010).

\section{Conclusion}

To evaluate the impact of PCDD/Fs emissions from a MSWI on the surrounding environment, a series of soil samples were collected from various sampling sites located $300-1,700 \mathrm{~m}$ away from the stack of the MSWI. The concentrations of PCDD/Fs in the ambient soil were relatively low. A contour map showed that a limited area surrounding the stack $(\leq 1,000 \mathrm{~m})$ was obviously influenced by PCDD/Fs emissions from the MSWI. Comparison with previous investigations conducted worldwide suggested that the emission concentrations of the incinerator and the distance from the stack were the main factors impacting the surrounding environment. Therefore, advanced pollution control facilities and strict emissions standards for PCDD/Fs should be adopted, and safe distances should be emphasized to protect human health and the environment from MSWI.

Acknowledgments This study was supported by the National 973 Program (2011CB201500), the Environmental Public Welfare Projects (201209019, 201109001), the National 863 Program (2012AA062803) and the National Natural Science Foundation of China (20977099, 21077121).

\section{References}

Brzuzy, L. P., \& Hites, R. A. (1995). Estimating the atmospheric deposition of polychlorinated dibenzo- $p$-dioxins and dibenzofurans from soils. Environmental Science and Technology, 29(8), 2090-2098. 
Carr, R., Zhang, C., Moles, N., \& Harder, M. (2008). Identification and mapping of heavy metal pollution in soils of a sports ground in Galway City, Ireland, using a portable XRF analyser and GIS. Environmental Geochemistry and Health, 30(1), 45-52.

Caserini, S., Cernuschi, S., Giugliano, M., Grosso, M., Lonati, G., \& Mattaini, P. (2004). Air and soil dioxin levels at three sites in Italy in proximity to MSW incineration plants. Chemosphere, 54(9), 1279-1287.

Cheng, P. S., Hsu, M. S., Ma, E., Chou, U., \& Ling, Y. C. (2003). Levels of PCDD/Fs in ambient air and soil in the vicinity of a municipal solid waste incinerator in Hsinchu. Chemosphere, 52(9), 1389-1396.

Dao, L., Morrison, L., Kiely, G., \& Zhang, C. (2012). Spatial distribution of potentially bioavailable metals in surface soils of a contaminated sports ground in Galway, Ireland. Environmental Geochemistry and Health, 1-12.

Domingo, J., Schuhmacher, M., Müller, L., Rivera, J., Granero, S., \& Llobet, J. (2000). Evaluating the environmental impact of an old municipal waste incinerator: PCDD/F levels in soil and vegetation samples. Journal of Hazardous Materials, 76(1), 1-12.

Fiedler, H. (1996). Sources of PCDD/PCDF and impact on the environment. Chemosphere, 32(1), 55-64.

Fries, G. F. (1995). A review of the significance of animal food products as potential pathways of human exposures to dioxins. Journal of Animal Science, 73(6), 1639-1650.

Gaus, C., Päpke, O., Dennison, N., Haynes, D., Shaw, G. R., Connell, D. W., et al. (2001). Evidence for the presence of a widespread PCDD source in coastal sediments and soils from Queensland, Australia. Chemosphere, 43(4), 549-558.

Kulkarni, P. S., Crespo, J. G., \& Afonso, C. A. M. (2008). Dioxins sources and current remediation technologies-A review. Environment International, 34(1), 139-153.

Kutz, F. W., Barnes, D. G., Bottimore, D. P., Greim, H., \& Bretthauer, E. W. (1990). The international toxicity equivalency factor (I-TEF) method of risk assessment for complex mixtures of dioxins and related compounds. Chemosphere, 20(7), 751-757.

Lee, S. J., Choi, S. D., Jin, G. Z., Oh, J. E., Chang, Y. S., \& Shin, S. K. (2007). Assessment of PCDD/F risk after implementation of emission reduction at a MSWI. Chemosphere, 68(5), 856-863.

Li, Y., Jiang, G., Wang, Y., Cai, Z., \& Zhang, Q. (2008). Concentrations, profiles and gas-particle partitioning of polychlorinated dibenzo- $p$-dioxins and dibenzofurans in the ambient air of Beijing, China. Atmospheric Environment, 42(9), 2037-2047.

Li, X., Yan, M., Chen, T., Lu, S., Yan, J., \& Cen, K. (2010). Levels of PCDD/Fs in soil in the vicinity of a medical waste incinerator in China: The temporal variation during 2007-2009. Journal of Hazardous Materials, 179(1), 783-789.

Liu, H., Lu, S., Buekens, A. G., Chen, T., Li, X., Yan, J., et al. (2012a). Baseline soil levels of PCDD/Fs established prior to the construction of municipal solid waste incinerators in China. Chemosphere, 86, 300-307.

Liu, W., Zhang, W., Li, S., Meng, C., Tao, F., Li, H., et al. (2012b). Concentrations and profiles of polychlorinated dibenzo- $p$-dioxins and dibenzofurans in air and soil samples in the proximity of a municipal solid waste incinerator plant. Environmental Engineering Science, 29(7), 693-699.

Lorber, M., Pinsky, P., Gehring, P., Braverman, C., Winters, D., \& Sovocool, W. (1998). Relationships between dioxins in soil, air, ash, and emissions from a municipal solid waste incinerator emitting large amounts of dioxins. Chemosphere, 37(9-12), 2173-2197.

Meneses, M., Schuhmacher, M., \& Domingo, J. (2002). A design of two simple models to predict PCDD/F concentrations in vegetation and soils. Chemosphere, 46(9-10), 1393-1402.

Ogura, I., Masunaga, S., \& Nakanishi, J. (2001). Congenerspecific characterization of PCDDs/PCDFs in atmospheric deposition: comparison of profiles among deposition, source, and environmental sink. Chemosphere, 45(2), 173-183.

Oh, J. E., Choi, S. D., Lee, S. J., \& Chang, Y. S. (2006). Influence of a municipal solid waste incinerator on ambient air and soil PCDD/Fs levels. Chemosphere, 64(4), 579-587.

Pirard, C., Focant, J. F., Massart, A. C., \& De Pauw, E. (2004). Assessment of the impact of an old MSWI. Part1: Level of $\mathrm{PCDD} / \mathrm{Fs}$ and PCBs in surrounding soils and eggs. Organohalogen Compounds, 66, 2059-2063.

Polder, A., Gabrielsen, G., Odland, J. Ø., Savinova, T., Tkachev, A., Løken, K., et al. (2008). Spatial and temporal changes of chlorinated pesticides, PCBs, dioxins (PCDDs/PCDFs) and brominated flame retardants in human breast milk from Northern Russia. Science of the Total Environment, 391(1), 41-54.

Rovira, J., Mari, M., Nadal, M., Schuhmacher, M., \& Domingo, J. (2010). Environmental monitoring of metals, PCDD/Fs and PCBs as a complementary tool of biological surveillance to assess human health risks. Chemosphere, $80(10)$, 1183-1189.

Schuhmacher, M., Granero, S., Llobet, J., De Kok, H., \& Domingo, J. (1997). Assessment of baseline levels of PCDD/F in soils in the neighbourhood of a new hazardous waste incinerator in Catalonia, Spain. Chemosphere, 35(9), 1947-1958.

Si, Z., Li, S., Huang, L., \& Chen, Y. (2010). Visualization programming for batch processing of contour maps based on VB and Surfer software. Advances in Engineering Software, 41(7), 962-965.

Wu, J., Dong, S., Liu, G., Zhang, B., \& Zheng, M. (2011). Cooking process: A new source of unintentionally produced dioxins? Journal of Agricultural and Food Chemistry, 59(10), 5444-5449.

Xu, M., Yan, J., Lu, S., Li, X., Chen, T., Ni, M., et al. (2009). Concentrations, profiles, and sources of atmospheric $\mathrm{PCDD} / \mathrm{Fs}$ near a municipal solid waste incinerator in Eastern China. Environmental Science and Technology, 43(4), 1023-1029.

Yan, J., Xu, M., Lu, S., Li, X., Chen, T., Ni, M., et al. (2008). $\mathrm{PCDD} / \mathrm{F}$ concentrations of agricultural soil in the vicinity of fluidized bed incinerators of co-firing MSW with coal in Hangzhou, China. Journal of Hazardous Materials, 151(2), 522-530.

You, H., Ding, J., Zhao, X. S., Li, Y. F., Liu, L. Y., Ma, W. L., et al. (2011). Spatial and seasonal variation of polychlorinated biphenyls in Songhua River, China. Environmental Geochemistry and Health, 33(3), 291-299. 